\title{
STRATEGI PENGEMBANGAN KAPASITAS KELEMBAGAAN POKMASWAS DI PROVINSI BANGKA BELITUNG
}

\author{
POKMASWAS INSTITUTIONAL CAPACITY DEVELOPMENT STRATEGY IN BANGKA \\ BELITUNG PROVINCE
}

\author{
Retfi Wiseli \\ Pengawas Perikanan Ahli Muda \\ email : wiseliretfi@gmail.com
}

\begin{abstract}
Abstrak
Penelitian ini bertujuan menggali informasi berbagai faktor dalam mendukung kinerja POKMASWAS serta memformulasi strategi pengembangan kapasitas kelembagaan POKMASWAS dalam memaksimalkan tugas dan fungsi pengawasan di lapangan khususnya di wilayah Provinsi Bangka Belitung. Metode analisis yang digunakan adalah SWOT analisis. Responden terdiri dari 5 (lima) Kelompok Masyarakat Pengawas yang ada di Kabupaten Bangka Tengah. Hasil penelitian diperoleh bahwa strategi pengembangan kapasitas kelembangaan POKMASWAS di Provinsi Bangka Belitung sebagai berikut: 1). Peningkatan kapasitas SDM anggota POKMASWAS dengan pembekalan dasardasar pengawasan; 2). Pelibatan POKMASWAS secara berkala dalam pengawasan terpadu; 3). Membentuk kerjasama POKMASWAS dengan lintas sektoral dan kelompok masyarakat lainnya; 4). Melakukan pertemuan kelompok secara reguler sebagai ajang evaluasi dan pengembangan; 5). Perlunya penetapan aturan lokal yang diinisiasi oleh POKMASWAS; 6). Melaporkan adanya pelanggaran secara tepat dan cepat agar dapat segera ditindaklanjuti oleh aparat penegak hukum; 7). Pembuatan dokumen AD/ART kelompok; 8). Menjalin kerjasama dengan perusahaan swasta (perusahaan sektor perikanan) agar dapat menjadi sponsor kegiatan POKMASWAS baik dalam pembiayaan dan dukungan sarana prasarana; 9). Dukungan pemerintah dalam mendukung keberadaan POKMASWAS; dan 10). Kemandirian POKMASWAS dalam pelaksanaan tugas.
\end{abstract}

Kata Kunci : Pokmaswas, Kelembagaan, Bangka Belitung,

\section{PENDAHULUAN}

Wilayah laut merupakan daerah akses publik (open acces) dan milik bersama (common property) yang berarti setiap orang mempunyai hak yang sama dalam menggunakan ruang laut (Fisher, et al. 2001 dalam Bidayani, et all. 2020). Penggunaan wilayah laut yang tidak terbatas dan terus menerus untuk sumber daya alam yang terbatas akan berakibat pada kerusakan sumber daya alam. Kegiatan pembangunan di wilayah daratan juga menyisakan berbagai macam permasalahan seperti pencemaran, gejala penangkapan ikan berlebihan (overfishing), penangkapan ikan dengan bahan peledak/racun/ setrum, penambangan terumbu karang yang digunakan sebagai bahan bangunan, degradasi fisik habitat pesisir, konflik pemanfaatan ruang dan lain sebagainya (Dahuri, 2001). Berbagai permasalahan tersebut jika tidak segera diatasi dan ditanggulangi akan berakibat buruk bagi kelangsungan sumber daya kelautan dan perikanan. Pengawasan merupakan salah satu cara untuk memutus berbagai praktek penyalahgunaan pemanfaatan wilayah laut yang tidak bertanggung jawab. Tanpa adanya pengawasan dan pemantauan dilapangan maka praktek penyalahgunaan pemanfaatan wilayah laut akan semakin liar dan buas (Nikijuluw dalam Naim, 2010).
Pengawasan tidak hanya dilakukan oleh lembaga maupun instansi pemerintah. Pengawasan dapat dilakukan oleh masyarakat itu sendiri.

POKMASWAS merupakan kepanjangan dari Kelompok Masyarakat Pengawas. POKMASWAS merupakan salah satu bentuk pengawasan yang melibatkan masyarakat. POKMASWAS diharapkan menjadi mitra pengawas perikanan dan berperan aktif dalam memberikan informasi serta melaporkan pelanggaran dalam pemanfaatan sumber daya kelautan dan perikanan kepada instansi terkait dan instansi penegak hukum (Dirjen PSDKP dalam Ratnawati, 2010). Namun di beberapa wilayah di Provinsi Kepulauan Bangka Belitung POKMASWAS belum bisa optimal dalam menjalankan tugas dan fungsinya sehingga diperlukan upaya untuk mengoptimalkannya. Tujuan dari penelitian ini adalah menggali informasi berbagai faktor dalam mendukung kinerja POKMASWAS serta memformulasi strategi pengembangan kapasitas kelembagaan POKMASWAS dalam memaksimalkan tugas dan fungsi pengawasan di lapangan khususnya di wilayah Provinsi Bangka Belitung. 


\section{METODE PENELITIAN}

\section{Waktu dan Lokasi Penelitian}

Penelitian ini dilaksanakan pada bulan Agustus 2020 dan berlokasi di wilayah Kabupten Bangka Tengah, yang diambil sebanyak 5 desa di 4 kecamatan (dari total 6 kecamatan, 56 desa) yakni Kecamatan Koba, Kecamatan Lubuk Besar, Kecamatan Namang dan Kecamatan Pangkalan Baru. POKMASWAS Dolphin yang berada di Kecamatan Koba, POKMASWAS Putra Tanjung dan POKMASWAS Bintang Kejora di Kecamatan Lubuk Besar, POKMASWAS Becampak di Kecamatan Namang dan POKMASWAS Batu Belubang di Kecamatan Pangkalan Baru.

\section{Jenis Penelitian}

Tipe penelitian ini adalah tipe penelitian bersifat deskriptif kualitatif yakni penelitian yang memberikan gambaran keadaan subjek/objek (lembaga masyarakat yakni POKMASWAS) pada saat sekarang berdasarkan fakta-fakta yang tampak sebagaimana adanya dengan menggunakan data primer dan data sekunder. Prosedur sampling terpenting adalah bagaimana menentukan informan kunci (key informan) yang sarat dengan informasi sesuai dengan fokus penelitian (Nawawi dalam Ratnawati, 2010). Total POKMASWAS yang ada di Kabupaten Bangka Tengah sebanyak 7 (tujuh) POKMASWAS, dan dilakukan sampling sebanyak 5 (lima) POKMASWAS.

\section{Analisa Data}

Analisis data yang digunakan dalam penelitian ini adalah menggunakan analisis SWOT. Setelah dilakukan penelitian maka akan didapat 4 (empat) alternatif strategi utama. Penentuan strategi dilakukan dengan mencari strategi silang dari keempat faktor yang ada, yaitu strategi Strenght-Opurtunities, Weakness-Opportunity, Strenght-Threats dan Weakness-Threats (Uktolseja et all dalam Yuliana, Anna et all, 2018).

Strategi silang dari 4 (empat) faktor yang ada (Rangkuti, 2006 dalam Anggun, 2017) yaitu :

1) Strategi $\mathrm{SO}$

Strategi ini disusun dengan memanfaatkan seluruh kekuatan untuk memanfaatkan peluang yang sebesar-besarnya.

2) Strategi ST

Maksud dari strategi ini yaitu menggunakan kekuatan yang dimiliki untuk mengatasi ancaman.

3) Strategi WO

Strategi ini didasarkan pada pemanfaatan peluang yang ada untuk meminimalkan kelemahan.

4) Strategi WT

Merupakan strategi yang bersifat defensif dengan meminimalkan kelemahan yang ada dan menghindari ancaman.

Setelah diperoleh strategi tersebut, maka diambillah keputusan dalam menentukan strategi yang paling mengguntungkan, efektif dan efisien bagi kelompok masyarakat pengawas (POKMASWAS) dan disusun untuk dijadikan pegangan dalam melakukan kegiatan selanjutnya.

Tabel 1. Tabel Alternatif Strategi

\begin{tabular}{|c|c|c|}
\hline & Opportunities $(\mathrm{O})$ & Threats $(\mathrm{T})$ \\
\hline \multirow[t]{2}{*}{ Strenght $(\mathrm{S})$} & Strategi SO & Strategi ST \\
\hline & 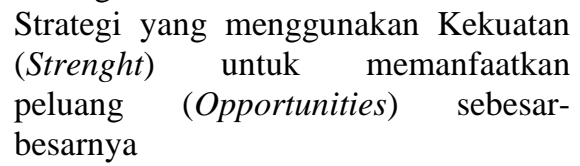 & $\begin{array}{lcr}\text { Strategi } & \text { yang menggunakan } \\
\text { Kekuatan } & (\text { Strenght }) & \text { untuk } \\
\text { mengatasi ancaman (Threats) } & \end{array}$ \\
\hline \multirow[t]{3}{*}{ Weakness (W) } & Strategi WO & Strategi WT \\
\hline & Strategi yang meminimalisasi & meminimalisai \\
\hline & $\begin{array}{l}\text { kelemahan (Weakness) untuk } \\
\text { memanfatkan peluang (Opportunities) }\end{array}$ & $\begin{array}{l}\text { kelemahan (Weakness ) untuk } \\
\text { menghindari ancaman (Threats) }\end{array}$ \\
\hline
\end{tabular}

Sumber : Rangkuti. 2000 dalam Neliyanti et all, 2017 


\section{HASIL DAN PEMBAHASAN}

Wilayah Kabupaten Bangka Tengah terletak $105^{\circ} 75^{\prime}$ BT $-106^{\circ} 80^{\prime}$ BT dan $2^{\circ} 20^{\prime} \mathrm{LS}-2^{\circ} 80^{\prime} \mathrm{LS}$, dengan luas wilayah sebesar $2.126,76 \mathrm{~km}^{2}$ atau 212.676,3 ha dan terbagi menjadi 6 Kecamatan yakni Kecamatan Koba, Kecamatan Pangkalan Baru, Kecamatan Sungai Selan, Kecamatan Simpang Katis, Kecamatan Namang dan Kecamatan Lubuk Besar (Pemkab Bateng, 2018). Wilayah Kabupaten Bangka Tengah merupakan wilayah paling banyak kasus pelanggaran di Bidang Kelautan dan Perikanan tercatat dari tahun 2015-2018 (DKP Bangka Belitung, 2019). Disinilah perlunya perlunya pendekatan terhadap peran penting anggota POKMASWAS dalam membantu pengawasan. Jumlah POKMASWAS yang ada di Kabupaten Bangka Tengah sebanyak 9 (Sembilan) Kelompok dari total 63 (enam puluh tiga) POKMASWAS yang ada di Provinsi Kepulauan Bangka Belitung.

masyarakat pengawas (POKMASWAS) seperti pada Tabel 2 dibawah ini :

Tabel 2 . Identifikasi Isu Utama Pengembangan POKMASWAS

\begin{tabular}{|c|c|c|}
\hline No & Isu Utama & Variabel \\
\hline 1 & $\begin{array}{l}\text { Keanggotaan } \\
\text { POKMASWAS }\end{array}$ & $\begin{array}{l}\text { 1. Semakin Bertambah } \\
\text { 2. Tetap } \\
\text { 3. } \text { Mengalami penurunan }\end{array}$ \\
\hline 2 & $\begin{array}{l}\text { Unsur anggota } \\
\text { POKMASWAS }\end{array}$ & $\begin{array}{l}\text { 1. Tokoh Agama, Tokoh Masyarakat, Nelayan, Pengusaha } \\
\text { Perikanan } \\
\text { 2. Tokoh masyarakat, Tokoh Anggama dan Nelayan } \\
\text { 3. Nelayan dan Pengusaha Perikanan }\end{array}$ \\
\hline 3 & $\begin{array}{l}\text { Tingkat Pemahaman } \\
\text { Anggota POKMASWAS }\end{array}$ & $\begin{array}{ll}\text { 1. } & \text { Sangat Paham } \\
\text { 2. } & \text { Cukup Paham }\end{array}$ \\
\hline 4 & $\begin{array}{l}\text { Tata Laksana (Dokumen } \\
\text { AD/ART) }\end{array}$ & $\begin{array}{l}\text { 1. Ada dan Tertulis } \\
\text { 2. Ada tetapi tidak tertulis }\end{array}$ \\
\hline 5 & $\begin{array}{l}\text { Pembiayaan /Dana } \\
\text { Opersional Kelompok }\end{array}$ & $\begin{array}{l}\text { 1. Dana Pribadi } \\
\text { 2. Dana Pemerintah } \\
\text { 3. Dana Swadaya }\end{array}$ \\
\hline 6 & Sarana dan Prasarana & $\begin{array}{l}\text { 1. Sarana Pokok } \\
\text { 2. Sarana Penunjang }\end{array}$ \\
\hline 7 & Peran Pemerintah & $\begin{array}{ll}\text { 1. } & \text { Sangat Mendukung } \\
\text { 2. } & \text { Cukup aktif mendukung }\end{array}$ \\
\hline
\end{tabular}

Sumber : Pengolahan data primer (2020)

Berdasarkan tabel 2 diatas, berbagai isu diatas merupakan faktor-faktor yang diduga berpengaruh terhadap kinerja POKMASWAS dalam pelaksanaan tugasnya. Berikut ini berbagai permasalahan dalam pengembangan POKMASWAS yakni :

\section{Keanggotaan POKMASWAS}

Anggota POKMASWAS yang ada di Kabupaten Bangka Tengah masih terdapat
POKMASWAS merupakan implementasi dari sistem pengawasan masyarakat (SISMASWAS), kelompok masyarakat yang mempunyai tugas dalam pengawasan sumberdaya kelautan dan perikanan. POKMASWAS diharapkan mampu memberikan informasi serta melaporkan pelanggaran-pelanggaran dalam pengelolaan dan pemanfaatan sumberdaya kelautan dan perikanan kepada instansi penegak hukum. POKMASWAS diharapkan mampu menjadi mitra pengawas perikanan dalam pengelolaan dan pemanfaatan sumberdaya kelautan dan perikanan secara bertanggung jawab sehingga diperoleh manfaat secara berkelanjutan (Dirjen PSDKP, 2006).

Berbagai permasalahan dan faktor penghambat pengembangan POKMASWAS, sehingga perlu diidentifikasi sehingga tidak menimbulkan permasalahan yang lebih besar dikemudian hari. Berikut isu utama dalam pengembangan kelompok 
kedepannya diharapkan lebih jelas dan terarah, sehingga tidak aka nada lagi anggota kelompok yang keluar dari kelompoknya. POKMASWAS di Kabupaten Bangka Tengah sudah dikukuhkan dengan SK Bupati pada Tahun 2014 dan SK Bupati Tahun 2016, POKMASWAS sudah memiliki kekuatan hukum dalam pelaksanakan tugasnya. Selain itu juga POKMASWAS saat ini sudah dilengkapi dengan kartu anggota POKMASWAS sehingga anggota kelompok mempunyai identitas saat melakukan pengawasan dan pendekatan kepada masyarakat yang tidak taat aturan.

2. Unsur anggota POKMASWAS

POKMASWAS merupakan pelaksana pengawasan di tingkat lapangan yang terdiri dari unsur tokoh masyarakat, tokoh agama, tokoh adat, LSM, nelayan, petani ikan serta masyarakat maritim lainnya. Semua unsur tersebut diharapkan mampu mendukung kinerja POKMASWAS di lapangan, Kelembagaan lokal berbasis masyarakat seperti POKMASWAS diharapkan mampu meredam konflik-konflik diwilayah pengawasan masing-masing dengan keberadaan berbagai unsur seperti unsur tokoh agama, tokoh masyarakat, tokoh adat, LSM, nelayan dan petani ikan. Keberadaan POKMASWAS di masyarakat diharapkan sebagai alat kontrol sosial masyarakat dalam berprilaku dan bertindak (Daris L, 2012).

3. Tingkat Pemahaman Anggota POKMASWAS

Belum semua anggota paham akan tugas dari POKMASWAS, hal ini menandakan bahwa tidak semua anggota mengatahui tujuan dan tugas POKMASWAS. Masih ada anggota POKMASWAS yang belum mengetahui tugas dan peranannya dalam kelompok. Sosialisasi dan pembinaan dirasa perlu sebagai bentuk penyadartahuan anggota POKMASWAS tentang tugas dan peranan kelompok dalam pemanfaatan sumberdaya kelautan dan perikanan guna pemanfaatan berkelanjutan. Belum adanya rasa memiliki kelompok terhadap arti penting dan nilai manfaat dari pengelolaan sumber daya kelautan dan perikanan.

4. Tata Laksana (Dokumen AD/ART)

POKMASWAS yang ada di Kabupaten Bangka Tengah belum memiliki sistem pembukuan dan pencatatan administrasi yang lengkap. Tidak memiliki perencanaan menandakan berati tidak ada perencanaan yang baik. Perencanaan merupakan tahap awal dalam mekanisme pengelolaan komunikasi atau informasi dalam suatu kelompok. Jika perencanaan disusun dengan baik dan matang, maka pada hakikatnya, pelaksanaan komunikasi suatu kelompok dianggap berhasil. Apabila perencanaan kurang baik, maka sulit untuk mencapai keberhasilan secara optimal, bahkan cenderung mengalami kegagalan atau hasil yang sangat minimal. Perencanaan Menurut Bintoro Tjokroaminoto dalam Firzal, Y, 2010, adalah proses mempersiapkan kegiatan-kegiatan secara sistimatis yang akan dilakukan untuk mencapai tujuan tertentu.

Komitmen bersama merupakan faktor yang harus dimiliki oleh organisasi, karena komitmen bersama berkaitan dengan komitmen dari unsurunsur pendukung dalam pengembangan kapasitas kelembagaan. Menurut teori pengembangan kapasitas mengenai pelaksanaan praktis yang diungkapkan oleh (Milen, 2006:17) dalam Dwihastari, S. 2017 salah satunya adalah penguatan kapasitas membutuhkan waktu yang lama dan memerlukan komitmen jangka panjang dan semua pihak yang terlibat. Perencanaan dan komitemen bersama seluruh anggota kelompok dituangkan dalam bentuk AD dan ART.

5. Pembiayaan/Dana Operasional Kelompok

Tidak ada pembiayaan khusus bagi POKMASWAS dan anggota dalam melaksanakan tugas pengawasan dilapangan, sehingga diperlukan cara agar kegiatan POKMASWAS ini bisa mendapatkan bantuan pembiayaan/ dana baik dari pemerintah dan pihak swasta. Kegiatan yang dilakukan POKMASWAS selama ini menggunakan dana pribadi berasal dari sumbangan anggota kelompok.

6. Sarana dan Prasarana

Keterbatasan sarana dan prasarana yang digunakan dalam mendukung kinerja POKMASWAS merupakan salah satu faktor yang menghambat. Sarana dan prasarana penting dalam pengawasan, tapa adanya sarana dan prasarana akan menyulitkan dalam pengawasan dilapangan. POKMASWAS yang ada di Kabupeten Bangka Tengah hanya memiliki sebagaian sarana prasarana pendukung seperti : telepon/HP, radio SSB, dan GPS, sebagian kelompok sarana dan prasarananya sudah mengalami kerusakan. Sarana prasarana tersebut tergolong minim, selayaknya dilengkapi dengan sarana pokok seperti : kapal. alkom (SSB, HT, HP) dan kamera, sarana penunjang yakni baju pelampung teropong, senter, mesin tik/computer, GPS dan Peta. Prasarana yakni tempat pertemuan guna memudahkan koordinasi dengan anggota kelompok. 


\section{Peran Pemerintah}

Peran masyarakat dalam pelaksanaan sistem pengawasan sumberdaya kelautan dan perikanan, merupakan jawaban dari keterbatasan pengawas perikanan yang dimiliki oleh Dinas Kelautan dan Perikanan Provinsi Kepulauan Bangka Belitung. Keberadaan POKMASWAS yang terkait dalam satu kepentingan yang sama yakni mejaga kelestarian sumberdaya kelautan dan perikanan (Daris, L, 2012). Partisipasi masyarakat dan pelibatan semua institusi dalam pengawasan merupakan kunci kesuksesan dalam pengelolaan kelestarian laut (Normasari et all, 2019). POKMASWAS yang ada di Kabupaten Bangka Tengah merasakan dukungan pemerintah terhadap kelompoknya dengan adanya pembinaan yang dilakukan Pemerintah Provinsi Kepulauan Bangka Belitung dengan pemberian kartu tanda anggota POKMASWAS, pembagian brosur berisi biota laut yang dilindungi dan himbauan untuk menjaga terumbu karang.

\footnotetext{
Berdasarkan identifikasi terhadap permasalahan-permasalahan dalam pengembangan POKMASWAS, maka disusun strategi pengembangan POKMASWAS yang dianalisis menggunakan metode SWOT. Adapun hasil analisa SWOT disajikan pada tabel di bawah ini :
}

Tabel 3. Matriks Strategi Pengembangan POKMASWAS di Provinsi Kepulauan Bangka Belitung

$\begin{array}{ll}\text { Opportunities }(\mathrm{O}) & \\ \text { 1. Penyadartahuan masyararakat } & \\ & \text { tentang arti penting sumberdaya } \\ & \text { kelautan dan perikanan yang } \\ & \text { berkelanjutan baik oleh pemerintah } \\ & \text { maupun pihak lain } \\ \text { 2. } & \text { Kebijakan at pengembangan } \\ & \text { POKMASWAS dalam } \\ \text { pembangunan wilayah pesisir dan } \\ \text { pulau-pulau kecil }\end{array}$

Opportunities $(\mathrm{O})$

kelautan dan perikanan yang berkelanjutan baik oleh pemerintah maupun pihak lain

POKMASWAS pulau-pulau kecil

\section{Threats $(\mathrm{T})$}

1. Berkurangnya keanggotaan dan tidak aktifnya POKMASWAS

2. Timbulnya konflik pemanfaatan ruang laut sektor Kelautan dan Perikanan

3. Makin maraknya pelanggaran di Bidang Kelautan dan Perikanan

\section{Strenght $(\mathrm{S})$ \\ 1. $\mathrm{SK}$ Pengukuhan \\ POKMASWAS sebagai aspek legal \\ 2. POKMASWAS sudah dilengkapi dengan Kartu Tanda Anggota (KTA) POKMASWAS yang diterbitkan oleh Kementerian Kelautan dan Perikanan RI. \\ 3. Dukungan Pemerintah Provinsi terhadap POKMASWAS}

\footnotetext{
Weakness (W)

1. POKMASWAS belum memiliki rencana kerja tertulis seperti dokumen AD/ART

2. Tingkat Pemahaman anggota kelompok masih kurang

3. Tidak memiliki sumber pembiayaan kelompok yang tetap

4. Terbatasnya sarana dan prasana pendukung POKMASWAS
}

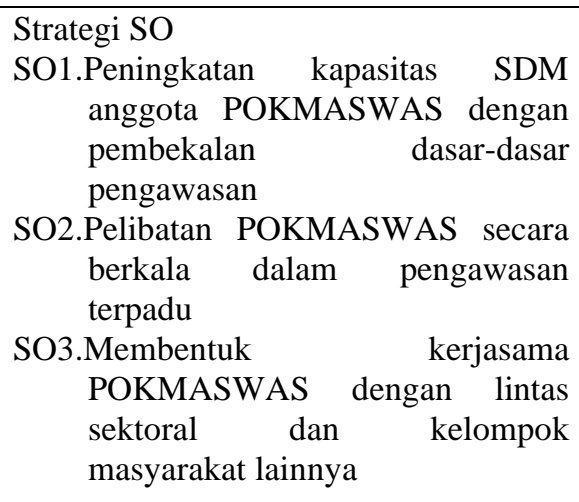

Strategi WO

WO1.Pembuatan dokumen AD/ART kelompok

WO2.Menjalin kerjasama dengan perusahaan swasta (perusahaan sektor perikanan) agar dapat menjadi sponsor kegiatan POKMASWAS baik dalam pembiayaan dan dukungan sarana prasarana
Strategi ST

ST1.Melakukan pertemuan kelompok secara reguler sebagai ajang evaluasi dan pengembangan

ST2.Perlunya penetapan aturan lokal yang diinisiasi oleh POKMASWAS

ST3.Melaporkan adanya pelanggaran secara tepat dan cepat agar dapat segera ditindaklanjuti oleh aparat penegak hukum

Strategi WT

WT1.Dukungan pemerintah dalam mendukung keberadaan POKMASWAS

WT2.Kemandirian POKMASWAS dalam pelaksanaan tugas 
Strategi yang dihasilkan dalam kajian ini terdapat 10 (sepuluh) poin yakni :

1. Peningkatan kapasitas SDM anggota POKMASWAS dengan pembekalan dasar-dasar pengawasan

Peningkatan kapasitas SDM untuk anggota POKMASWAS ini dipandang perlu guna meningkatkan kemampuan masyarakat dalam membantu pemerintah dalam pengawasan dilapangan, mengingat sebagian besar anggota POKMASWAS merupakan nelayan yang umumnya tingkat pendidikan rendah (Pakpahan et al. 2006 dalam Yuliana et al 2012). Dasar-dasar pengawasan yang hars dimiliki oleh anggota POKMASWAS yakni : tugas dan wewenang POKMASWAS, pengenalan jenis-jenis ikan yang dilindungi, penggunaan alat tangkap yang dilarang untuk digunakan, sanksi hukum atas pelanggaran yang dilakukan oleh pelaku usaha kelautan dan perikanan yang melanggar.

2. Pelibatan POKMASWAS secara berkala dalam pengawasan terpadu

Keiikutsertaan POKMASWAS dalam melakukan pengawasan dilapangan dirasa penting guna menumbuhkan rasa memiliki akan pentingnya pelestarian sumber daya alam. Sumber daya alam tidak akan bisa pulih dengan cepat apabila ekosistem perairan tersebut sudah rusak. Pentingnya menumbuhkan rasa kesadaran dalam mengelola dan melestarikan lingkungan alam sebagai dasar untuk membawa perubahan yang lebih besar (Maulidah et al. 2018). Salah satu cara untuk meningkatkan rasa memiliki akan keberadaan ekosistem perairan yakni dengan melibatkan POKMASWAS dalam pengawasan terpadu dengan menggunakan kapal patroli pengawas, kegiatan lain seperti : penanaman mangrove dan terumbu karang.

3. Membentuk kerjasama POKMASWAS dengan lintas sektoral dan kelompok masyarakat lainnya

POKMASWAS merupakan salah satu unsur yang memanfaatakan sumber daya kelautan dan perikanan, ada juga kelompok masyarakat sadar wisata (POKDARWIS), dan kelompok karang taruna yang ada di Desa. Kerjasama tersebut diharapkan mampu bersinergi dalam mendukung pengawasan penggunaan sektor kelautan dan perikanan dari berbagai macam praktek yang bertentangan dengan aturan.

4. Melakukan pertemuan kelompok secara reguler sebagai ajang evaluasi dan pengembangan

Pertemuan kelompok secara reguler sebaiknya diakukan secara rutin guna meningkatakan pengetahuan anggota kelompok, selain itu juga bisa dijadikan ajang evaluasi dan pengembangan
POKMASWAS kedepannya. Kemampuan POKMASWAS untuk mendeteksi dan melaporkan adanya dugaan pelanggaran, juga harus didukung dengan keterampilan berkomunikasi. Oleh karena itu, pentingnya pertemuan dan diskusi yang dilakukan POKMASWAS. Pertemuan sebaiknya dilakukan paling tidak seminggu sekali, dalam pertemuan tersebut sebaiknya diisi dengan penyamaan persepsi serta pemahaman POKMASWAS dalam melaksanakan tugas pengawasan. POKMASWAS ini juga diharapkan mampu memberikan informasi bagi masyarakat lain yang bukan anggota guna pemahaman kepatuhan prilaku taat terhadap aturan yang tentu saja melibatkan mayarakat secara luas.

5. Perlunya Penentapan Aturan Lokal yang diinisiasi oleh POKMASWAS

Konflik yang sering terjadi antar pengguna ruang laut sektor kelautan dan perikanan terkadang menjadi sulit untuk diselesaikan. Penetapan aturan lokal masyarakat setempat merupakan aturan yang dibuat oleh masyarakat terkait kegiatan yang diperbolehkan dan kegiatan yang dilarang untuk dilakukan diwilayah perairan tersebut, sehingga pelaku usaha yang tidak mematuhi aturan lokal yang telah diinisiasi oleh POKMASWAS akan mendapakatkan sanksi sesuai atauran yang ada.

6. Melaporkan adanya pelanggaran secara tepat dan cepat agar dapat segera ditindaklanjuti oleh aparat penegak hukum

POKMASWAS yang aktif diharapkan mampu memberikan informasi yang tepat dan cepat, yang dilengkapi dengan dokumentasi dan laporan kejadian adanya pelanggaran. Dokumentasi kegiatan POKMASWAS selama ini masih kurang, hal inilah yang perlu diperbaiki. Jika pencatatan kegiatan POKMASWAS rapi, maka data-data tersebut dapat berguna bagi POKMASWAS dan instansi terkait lainnya (Yuliana. et al. 2012). POKMASWAS juga bersedia jika diperlukan untuk menjadi saksi oleh aparat penegak hukum.

7. Pembuatan dokumen AD/ART kelompok

Masih lemahnya sistem pencatatan POKMASWAS, belum adanya dokumen yang jelas terkait Anggaran Dasar dan Anggaran Rumah Tangga Kelompok, maka masih sangat diperlukan pembinaan dan bimbingan oleh Dinas Kelautan dan Perikanan Provinsi Bangka Belitung agar POKMASWAS memiliki sistem perencanaan kerja kelompok yang lebih terarah dan tercatat.

8. Menjalin kerjasama dengan perusahaan swasta (perusahaan sektor perikanan) agar dapat menjadi sponsor kegiatan POKMASWAS baik dalam pembiayaan dan dukungan sarana prasarana 
POKMASWAS yang sudah dilengkapi dengan dokumen AD/ART yang baik akan dengan mudah mencari dukungan untuk memperlancar jalannya tugas pengawasan baik berupa pembiayaan dan dukungan sarana prasarana dari pelaku usaha yang berkecimpung di bidang kelautan dan perikanan seperti : pelaku usaha tambak udang yang sedang marak-maraknya di wilayah Bangka Belitung dan pelaku usaha sektor pariwisata.

9. Dukungan pemerintah dalam mendukung keberadaan POKMASWAS

10. Kemandirian POKMASWAS dalam pelaksanaan tugas

POKMASWAS diharapkan bisa mandiri, tidak hanya berharap pada bantuan dari pemerintah, akan tetapi bisa tetap melaksanakan tugas pengawasan dengan sendirinya. Kemandirian

\section{KESIMPULAN}

\section{Kesimpulan}

Berdasarkan hasil penelitian, dapat disimpulkan strategi pengembangan kapasitas kelembangaan POKMASWAS di Provinsi Bangka Belitung sebagai berikut : 1). Peningkatan kapasitas SDM anggota POKMASWAS dengan pembekalan dasar-dasar pengawasan; 2). Pelibatan POKMASWAS secara berkala dalam pengawasan terpadu; 3). Membentuk kerjasama POKMASWAS dengan lintas sektoral dan kelompok masyarakat lainnya; 4). Melakukan pertemuan kelompok secara reguler sebagai ajang evaluasi dan pengembangan; 5). Perlunya penetapan aturan lokal yang diinisiasi oleh POKMASWAS; 6). Melaporkan adanya pelanggaran secara tepat dan cepat agar dapat segera ditindaklanjuti oleh aparat penegak hukum; 7). Pembuatan dokumen AD/ART kelompok; 8). Menjalin kerjasama dengan perusahaan swasta

\section{DAFTAR PUSTAKA}

Anggun, Charisma Defi. 2017. Rencana Strategis Kelompok Masyarakat Pengawas (POKMASWAS) Gemuruh Kecamatan Muncar Kabupaten Banyuwangi Jawa Timur. Universitas Brawijaya Malang. Malang

Bidayani, Endang dan Kurniawan. 2020. Resulusi Konflik Pemanfaatan Sumberdaya Pesisir antara Nelayan dan Penambang Timah Inkonvensional. Society. 8(1):14-24.

Dahuri, Rokhimin. 2001. Pengelolaan Ruang Wilayah Pesisir dan Lautan Seiring dengan Pelaksanaan Otonomi Daerah. Bandung. Mimbar. 18 (2): 139-171.
Dukungan penuh Pemerintah Provinsi Kepuluan Bangka Belitung agar keberadaan POKMASWAS tetap aktif mendukung pengawasan. Dukungan kepada POKMASWAS dapat berupa : bantuan sarana prasarana, pembinaan dan penyuluhan dalam penyusunan dokumen POKMASWAS yakni dokumentasi dan pelaporan.

kelompok bisa diinisasi melalui iuran bulanan yang tertulis dalam dokumen AD/ART berdasarkan kesepakatan bersama anggota, gotong royong dalam pembangunan tempat pertemuan atau bantuan terhadap anggota kelompok, sehingga POKMASWAS kemandirian bisa tercipta.

(perusahaan sektor perikanan) agar dapat menjadi sponsor kegiatan POKMASWAS baik dalam pembiayaan dan dukungan sarana prasarana; 9). Dukungan pemerintah dalam mendukung keberadaan POKMASWAS dan 10). Kemandirian POKMASWAS dalam pelaksanaan tugas.

\section{UCAPAN TERIMA KASIH}

Ucapan terima kasih disampaikan kepada Bapak Jimmy Margomgom T dan Ibu Hasti Wahyuni yang sudah membantu memberikan bantuan pemikirannya, sengenap jajaran di Bidang Pengawasan Sumberdaya Kelautan dan Perikanan Provinsi Kepulauan Bangka Belitung. Terima kasih juga disampaikan kepada Tim Akuatik Jurnal terkhusus Jemmy Ferizal dan Bapak Sudirman Adibrata yang sudah banyak membantu.

Daris, Lukman. 2012. Peran Kelembagaan Lokal dalam Penyelesaian Konflik Pemanfaatan Sumberdaya Perikanan Tangkap di Wilayah Pesisir Kabupaten Maros. Jurnal Balik Diwa. 3(2):1-12.

Direktorat Jenderal Pengawasan dan Pengendalian Sumberdaya Kelautan dan Perikanan Departemen Kelautan dan Perikanan Republik Indonesia. Kebijakan Pengawasan dalam Penganggulangan Illegal. Unreported and Unregulated (IUU) Fishing. (Jakarta: Departemen Kelautan dan Perikanan, 2006).

Dwihastari, S. 2017. Analisis Pengembangan Kapasitas Kelembagaan pada Badan Kepegawaian, Pendidikan dan Pelatihan Kota Semarang. Semarang. 
Firzal, Y. 2010. Konsep Dasar Perencanaan. https://yusrizalfirzal.wordpress.com. september 2020].

Maulidah, Siti. Hermanto. 2018. Kelompok Masyarakat Pengawas (POKMASWAS): Kesadaran Ekologi Masyarakat Desa Labuhan Kecamatan Brondong Kabupaten Lamongan dalam Menjaga Ekosistem Pantai Kutang. UNESA. Kajian Moral dan Kewarganegaraan. 06(3): 1106-1120.

Naim, Armain. 2010. Penanganan Sumber Daya Perikanan dalam Penanganan Illegal Fishing di Perairan Maluku Utara. [Tesis] Program Pasca Sarjana Universitas Terbuka Jakarta. Jakarta.

Neliyanti, Agussabti, dan Indra. 2017. Analisis Tingkat Partisipasi Anggota Pokmaswas dalam Pengawasan Sumberdaya Kelautan dan Perikanan (Studi Kasus di Kota Sabang). Aceh, 13 April 2017. Hlm.:B181-B189.

Normasari Erma., Lewis S., Iqbal M., Putra H., 2018. Peran Masyarakat dalam Konservasi : Sebuah Studi dari Perikanan Hiu dan Pari Mobulids di Indonesia. Halaman 301-306.

Pemerintah Kabupaten Bangka Tengah. 2018. Profil Daerah Kabupaten Bangka Tengah. Site Resmi Pemerintah Kabupaten Bangka Tengah. https://bangkatengahkab.go.id [29 september 2020].

Ratnawati. 2010. Studi Pengembangan Kapasitas Institusional Pokmaswas dalam Pengelolaan Sumber Daya Terumbu Karang di Kabupaten Pangkep. Jurnal Spasial. 8(1): 52-59.

Sari, N. A. 2018. Faktor-Faktor yang Mempengaruhi Ketertarikan pada Organisasi dan Intensi untuk
Mendapatkan Perkerjaan : Jenis Kelamin sebagai Variabel Moderasi. Jurnal Manajemen Bisnis dan Inovasi. 5(1):64-74.

Yuliana, Anna., Wibowo, B.A., Dian, Aristi. P.F. 2018. Analisis Kinerja Pengawas Perikanan dalam Penerapan Monitoring, Controling and Surveillance (Studi Kasus di Pangkalan PSDKP Jakarta). Journal of Fisheries Resources Utilization Management and Technologi. 7(4):39-48.

Yuliana Ernik,. Winata, Adi. 2012. Pengaruh Karakteristik dan Persepsi terhadap tingkat Partisipasi Anggota dalam Kelompok Masyarakat Pengawas (POKMASWAS) Sumberdaya Kelautan dan Perikanan. Jurnal Bumi Lestari. 12 (2):251-259. 